\title{
LO ANDINO Y LA DISCRIMINACION (INCLUIDAS LAS MUJERES) EN CUSCO
}

\section{THE ANDEAN CONDITION AND DISCRIMINATION (INCLUDING WOMEN) IN CUSCO}

\author{
Jesús José Solís Mora(1) \\ Universidad Nacional de San Antonio Abad del Cusco, Perú
}

\begin{abstract}
Resumen: Este articulo trata de esclarecer el concepto de lo andino en su dinámica histórica, sus componentes y cómo se evidencia su aplicación a cargo de las poblaciones indígenas y mestizas a nivel urbano y rural. También aborda las influencias de la globalización y como lo andino que se viven en la ciudad del Cusco, Perú. El otro tema es la discriminación existente contra los pueblos originarios andinos y sus expresiones contra la población migrante y de manera especial como esta marginación se da contra las mujeres indígenas por su condición de género.
\end{abstract}

Palabras claves: Cultura Andina, Indígenas, Cusqueñismo, Discriminación, Género.

\begin{abstract}
This article tries to clarify the concept of the Andean condition in its historical dynamics, its components, and how it is showed by indigenous and mestizo populations at urban and rural areas. It also addresses the influences of globalization and how Andean people live its effects at Cusco, Peru. The other issue is the existing discrimination against the Andean native peoples and their expressions against the migrant population and especially how this marginalization occurs against indigenous women because of their gender status.
\end{abstract}

Keywords: Andean Culture, Indigenous, Cusqueñismo, Discrimination, Gender.

(1) Antropólogo, docente universitario de la UNSAAC, consultor en desarrollo rural. 


\section{Introducción}

El presente ensayo es parte de una investigación más amplia sobre los temas de cultura andina, discriminación e identidad en el Cusco que durante cinco años hemos realizado entre la población urbana mestiza, campesinos indígenas, migrantes y estudiantes de nuestra universidad de origen provinciano, donde indagamos sus percepciones y practicas sobre lo andino y su correlato discriminatorio e identitario; es así como fuimos encontrando respuestas bien sorprendentes sobre la vigencia de la cultura andina compartida por mestizos e indígenas, pero al mismo tiempo procesos de discriminación y racismo entre estos grupos étnico-culturales mezclados con percepciones de clase social. En el primer caso de compartición cultural resalta el orgullo cusqueñista de ser descendientes de lo inca; en el segundo caso, se aprecia la reproducción de ideologías coloniales, donde el tema de discriminación contra las mujeres (de origen indígena) es relevante.

\section{2. ¿Qué es lo andino?}

Lo andino lo entendemos como el conjunto de culturas que se desarrollaron antes de la presencia europea en la cordillera de los andes aproximadamente hace 12,000 años, situación geográfica ambiental tan compleja como variada ${ }^{(2)}$ que marcó la configuración cultural de los pueblos originarios que construyeron y humanizaron este espacio para dar origen a infinidad de culturas locales, cuyo desarrollo se plasmó en las grandes civilizaciones andinas. En el caso peruano este proceso de culturización y transformación del paisaje dio origen desde hace 5,000 años a la cultura andina, que de manera determinante es la matriz cultural de nuestro país, donde los antiguos peruanos a lo largo de los siglos han construido las culturas pre incas e inca que luego han sufrido cambios trascendentales hasta nuestros días. Para entender el significado de lo andino Rodrigo Montoya (1980) hizo una formulación en el sentido de que se halla compuesto de tres vertientes: componente prehispánico recreado, el componente feudal y moderno (mito de la escuela), a cuyos elementos hemos añadido nuevos indicadores que resumimos:

a) Componente prehispánico recreado, compuesto por elementos culturales fragmentados o poco alterados, que continúan desde las culturas pre incas e inca hasta las actuales comunidades campesinas indígenas.

- Conservación de valores como el colectivismo, ayuda mutua

- Relaciones de reciprocidad aplicadas en la vida cotidiana

- El profundo valor hacia la fiesta

- Profunda relación hombre naturaleza expresada en la cosmovisión andina

(2) Compuesta de 11 ecoregiones, 8 regiones naturales, 93 climas y miles de ecosistemas que han producido una megabiodiversidad única en el mundo por su variabilidad y complejidad. 
- Creencias mágico religiosas y practica de rituales agro céntricos

- Conocimiento mítico de la sociedad y naturaleza, fuerte tradición oral

- Rituales de sanación combinados con la medicina tradicional y fitoterapia

- Profundo conocimiento de la agricultura de ladera (policultivos, rotación, asociaciones, indicadores de clima, refrescamiento de las semillas, sistemas de riego, sistemas de crianzas, manejo de agro ecosistemas, técnicas para el manejo de cobertura vegetal, manejo de herramientas tradicionales dando origen a economías de subsistencia y de producción orgánica y ecológica).

- Organización comunitaria basada en el consenso (asambleas, faenas)

- Control comunal de los recursos (laymes, agua, pastos, bosques)

- Vigencia de autoridades tradicionales y sistemas de justicia comunitaria

- Gestión del territorio (espacios sagrados, espacios sociales, poblaciones dispersas o núcleos poblacionales pequeños en distintos pisos ecológicos

- Autodefinición indígena quechua

- Profundo localismo (lucha por su territorio, orgullo de sus costumbres)

b) Componente colonial, son los_elementos asimilados por los indígenas de manera forzada de la cultura española que luego dio origen a un sincretismo o yuxtaposición de elementos prehispánicos con los coloniales, entre estos tenemos:

- Fiestas patronales católicas de santos en cada pueblo

- Folclore: música, danzas, artesanía, gastronomía, vestidos tradicionales

- Instituciones: cabildos, sistema de autoridades (varayoq)

- Tecnologías, cultivos y crianzas (yunta, trigo, haba, vacunos, ovinos, etc.)

- Economía de subsistencia

- Ideologías coloniales: baja autoestima, aceptación de la desigualdad y marginación, aceptación de la superioridad mestiza-criolla, sumisión, fatalismo, pasividad frente a la injusticia y fatalismo y desvalorización de su cultura frente a las demás.

- Prejuicios, estereotipos: discriminación, racismo, exclusión, comprensión de la realidad solo desde la religión

- Exacerbación del localismo y rivalidades entre pueblos.

c) Componente moderno, fruto del proceso de articulación del mundo andino con la república, la introducción del capitalismo y la modernización 
de la sociedad que ha posibilitado para que los indígenas andinos asimilen y adapten elementos culturales como:

- El acceso a la educación, la castellanización

- El uso de tecnologías

- Articulación al mercado

- Costumbres, fiestas, bailes, música, artesanía, gastronomía y otros

- Relación con el gobierno y Estado para acceder a servicios básicos

- Ideologías y estilos de vida individualistas

Estos procesos han configurado a lo largo de los siglos la cultura andina en una amalgama acumulativa que solo ha sido posible a través de tres estrategias usadas por los indígenas para mantener la vigencia de su cultura: la resistencia, la asimilación y la innovación (Bonfil, 1990, pag.191).

La resistencia, entendida al proceso como los indígenas preservaron a lo largo de los siglos elementos culturales propios de sus culturas locales y de la civilización inca, que quedaron de la invasión en estado disperso y fragmentado, luego de una brutal dominación. Los indígenas mantuvieron en la clandestinidad mitos, ritos, conocimientos, practicas, tecnologías que fueron recreando y reconstruyendo a partir de su vida en comunidad; lo que demuestra la vigencia y continuidad de la cultura andina con sus propias particularidades.

La asimilación o adaptación, se refiere a los elementos culturales coloniales, republicanos y modernos que incorporaron los indígenas andinos a su matriz cultural prehispánica, produciendo un proceso llamado andinización que consistió en darle un sello propio al elemento externo y adecuarlo a las condiciones ecológicas, sociales y económicas de la cultura local. Esta adaptación es la forma como muchos saberes, tecnologías, creencias, fiestas, costumbres y formas de organización social se articularon en el sincretismo para analizar la combinación colonial y andina; a la cual se suma la vertiente moderna.

Finalmente, tenemos la innovación como práctica de creación e invención de los indígenas especialmente en el campo tecnológico y agropecuario que ha permitido aprovechar de manera óptima un conjunto de recursos escasos y oportunidades propias de dinámicas de interacción con otras culturas. La agricultura y ganadería andina es una prueba de ello, el folklore, la gastronomía, artesanía, fiestas, tradición oral y otros son evidencias que lo andino es dinámico, flexible, holístico y altamente simbólico.

En términos territoriales podemos afirmar que lo andino se halla vivo y vigente en las comunidades campesinas y su terca persistencia para subsistir en medio de tantos avatares históricos anti indígenas que trataron de desaparecerla, 
sustituirla y quitarle su esencia ${ }^{(3)}$. Son las comunidades las encargadas de conservar esta herencia cultural que luego se fue expandiendo a lo largo del país, no solamente por los indígenas sino por migrantes, mestizos urbanos, comerciantes, especialmente por intelectuales, artistas, literatos, poetas quienes se encargan de re-elaborarla, re-crearla y enriquecerla diseñando y reproduciendo lo que denominamos "identidad cultural andina".

No es casual que en las urbes y ciudades intermedias serranas y costeñas, lo andino se encuentre en cada expresión cultural que se contrasta con lo "no andino", léase extranjero, limeño o colonial, donde se va a resaltar la herencia pre hispánica con mucho orgullo, especialmente en el Cusco por haber sido capital de la civilización inca y con mayor razón en las fiestas del mes de junio.

Ahora bien, en la actualidad vivimos en un mundo globalizado y bajo la hegemonía del capitalismo neoliberal, donde la economía de mercado, el culto al dinero, la cultura extractivista, el estilo de vida norteamericano, el consumismo e individualismo viene penetrando en todos los rincones del planeta ¿Cómo afecta esta globalización en la cultura andina? ¿Cuánto más avanza el capitalismo salvaje más retrocede lo andino? ¿Lo andino está condenado a desaparecer por la influencia del mercado?

\section{Lo andino en tiempos globalizados}

Al ser la globalización un fenómeno económico, social, político y cultural a nivel mundial innegablemente su fuerza ha penetrado $y$ hegemonizado la sociedad peruana llegando a las comunidades andinas y amazónicas con sus bondades y principalmente aspectos perniciosos ${ }^{(4)}$; el problema está en conocer ¿Cuál es el impacto que viene ocasionando a la cultura andina? Definitivamente viene alterando y ocasionando severos cambios que se reflejan en los siguientes fenómenos socioeconómicos:

- Articulación de las comunidades a la economía de mercado, lo que se expresa en relaciones de asalariamiento, emprendimientos, alto consumo de insumos químicos, dependencia tecnológica, pequeña agricultura no rentable e ingresos campesinos mediante actividades no agropecuarias.

- Ocupación del territorio, mediante la urbanización acelerada, formación de nuevos centros poblados, desestructuración de comunidades, venta de tierras comunales.

(3) La constitución de la "república de españoles" y "de "indios" y la "pureza de sangre"en la colonia; la "solución bovina" a inicios del siglo XX y el "mestizaje cultural anti indígena" en el siglo XX-XXI.

(4) Transculturación por medio de los medios de comunicación, deterioro del medio ambiente, venta de la imagen, competitividad exacerbada, búsqueda insaciable de dinero, corrupción y valores egoístas. 
- Organizaciones comunitarias en crisis de representación, nadie quiere ser dirigente, flexibilización de los roles comunitarios y privatización de tierras colectivas bajo el predominio del interés individual y débil gestión de los recursos naturales.

- Estilos de vida, que se expresan en que los campesinos (indígenas) vienen masivamente migrando a la ciudad realizando inversiones en la ciudad (en educación, negocios y casas), bajo el paradigma de dejar de ser campesino (indígena) y tener acceso al consumo de bienes urbanos, a la informática, diversiones, ocio y esparcimientos.

- Identidades difusas y múltiples con conflictos identitarios (negaciónafirmación), procesos de aculturación y escapismos sociales (consumo de alcohol o incorporación a religiones evangélicas).

- Desinterés por ejercer la ciudadanía y participación política con un apoliticismo generalizado y sometimiento a prácticas clientelistas en épocas electorales.

Estos cambios estructurales vienen provocando también cambios en las ideologías, comportamientos, actitudes y prácticas sociales, económicas y políticas de la población indígena campesina y migrante, que impacta directamente en hechos culturales, sistema donde se evidencian tres procesos:

a. Proceso de aculturación profuso, donde los campesinos indígenas van incorporando, adoptando y adaptando elementos urbanos criollo-mestizos en sus formas de vivir y estilos de vida que se expresan en marcadores como vestido, música, lengua, bailes, diversiones, consumo, alimentación, pensamientos, valores y actitudes que los van convirtiendo en un estrato social intermedio entre lo indígena y lo criollo a lo que normalmente se denomina el segmento cholo, provinciano quien vive entre dos mundos sin desligarse de ninguno.

Estos grupos van a reproducir muchos elementos indígenas andinos en sus estilos de vida urbanos como relaciones de compadrazgo, reciprocidad, cooperación mediante organizaciones y asociaciones de paisanaje que les permite recrear lo comunitario en un contexto urbano-globalizado en cargos religiosos, fiestas patronales. Pero al mismo tiempo también van a ser "modernos" al combinarlos con oportunidades de negocio, redes sociales, consumo de alcohol, gastos en bienes, búsqueda de prebendas personales, logro personal a ultranza, oportunismos, clientelismo, estatus social mediante prácticas no éticas, corrupción o discriminación y racismo.

b. Des-indigenizacion creciente, se evidencia en situaciones en las que los andinos campesinos y migrantes vienen sufriendo -desde los grupos de poder- la 
imposición de políticas culturales orientadas a dejar de lado, ignorar o soslayar la presencia de pueblos indígenas y no dar paso a actividades de revitalización cultural indígena, menos a exigencias de derechos indígenas al Estado. Para ello han instrumentalizado sistemas educativos, medios de comunicación, procesos de enculturación para imponer la cultura oficial criollo-mestiza como paradigma nacional (léase como globalizada occidental-moderna) donde solo se proyecta el modelo costeño-citadino-extranjero ${ }^{(5)}$ a todo el país, de manera que "lo indígena" es tratado como de segundo orden, de mala calidad o finalmente subversivo. Por ello la arremetida para homogenizar la cultura y cortar espacios a las expresiones diversas, múltiples de la diversidad cultural andina, amazónica, afroperuana, de "todas las sangres".

En los casos en que ya es inevitable el reconocimiento de lo indígena, entonces se recurre a imágenes folklorizadas, estereotipadas mostrándolas como lo "exótico" viviente en las cordilleras, comunidades, tribus y grupos étnicos con sus "costumbres típicas" (danzas, comida, lengua, vestido y vivienda); donde la cultura indígena solo sirva para divertir o alegrar al visitante, pero no es considerado como actor social con necesidades, problemas, valores y principalmente derechos especiales que les corresponden.

c. "Blanqueamiento" cultural, esta situación deviene de un problema estructural que es la discriminación, el racismo, la exclusión social y la marginación producto de innumerables prejuicios y estereotipos construidos desde la época colonial, que se conservan y reinventan en tiempos globalizados, y atraviesan todo el tejido social de la sociedad peruana urbana y rural. En este contexto las víctimas son los indígenas, cholos, provincianos, migrantes, serranos quechuas o aymaras; quienes, para no seguir sufriendo agravios, dolor o sentirse mal, van a recurrir a estrategias de blanqueamiento social, como son:

- $\quad$ Educación: profesionalizarse o tecnificarse

- Trabajo esforzado para conseguir mayores ingresos

- Emprendimientos económicos

- Ocupar cargos públicos o políticos

- Adquirir bienes y ostentarlos

El resultado que buscan muchos indígenas con este blanqueamiento social es el de ser aceptado social y culturalmente y no ser víctima de discriminación y

(5) El identificar como música nacional al vals y a la música costeña no son casuales; las imágenes que se vende en la televisión son siempre blanco-criollo-costeño, donde lo andino, indígena no aparece y si lo hacen es de forma ridícula, estereotipada. Véase como se resalta las diferencias entre el capitalino vs el provinciano; la composición del parlamento donde el 99\% de los congresistas son mestizos de clase media y solo el $1 \%$ se reconoce indígena. La sobrevaloración de lo extranjero en términos de tecnología, modas, paradigmas artísticos. Todos sirven como pretexto para mostrar la supuesta superioridad de lo criollo sobre el resto de las culturas. 
exclusión social. El problema es que al "blanquearse" el andino reproduce el modelo dominante, no lo cuestiona, se adapta a él y termina finalmente conservando y reproduciendo el sistema.

¿Qué hacer entonces? ¿Es inevitable la desaparición de lo andino? Desde nuestra experiencia y reflexión consideramos que no es inevitable porque existen también muchas fuerzas que reman contra la corriente. Hay elementos de contra cultura, de revitalización cultural y afirmación de lo andino que se refleja en movimientos sociales, grupos intelectuales, juventudes indígenas migrantes que enarbolan lo andino, realizan funciones de teatro, danza, música, rituales, filosofía, literatura, creaciones artísticas plásticas, concursos, seminarios, eventos intelectuales, desfiles y muchas expresiones que bullen desde las comunidades más alejadas hasta las ciudades, todo desde la sociedad civil.

Por ello, consideramos que lo andino se halla bullendo con mucha vitalidad en los espacios rurales y no rurales de todo el país, pero principalmente a dos niveles:

Primero. Se mantiene vigente, con sus significados propios, en comunidades alejadas. A pesar de la feroz arremetida del colonialismo moderno, la continuidad de los elementos prehispánicos y españoles se conserva aún en muchas comunidades andinas. Dicha persistencia cultural, se halla articulada a un factor geográfico de suma importancia para los andes: la distancia y la lejanía, considerando que muchas comunidades se hallan ubicadas en lugares y espacios tan disimiles, diferenciados, alejados y muy accidentados cuyo vínculo con la sociedad mayor no es muy fluida, es esporádica, precisamente por las dificultades de acceso; entonces el vínculo entre el hombre y la naturaleza del indígena es poderoso. Ello es garantía de permanencia y continuidad cultural.

Tratándose el Cusco de una región netamente indígena, campesina agropecuaria $^{(6)}$, estimamos que un $30 \%$ de las comunidades no cuentan con medios de articulación vial entre las comunidades con el resto de la región. No olvidar que las interrelaciones económicas socioculturales y económicas son esencialmente entre comunidades y sus capitales de distrito o provincia políticas que permite ampliar sus identidades y reforzar los localismos. En ese sentido, se constata que la distancia geográfica es un factor determinante para la persistencia y continuidad de elementos de la matriz andina en las comunidades campesinas andinas, que son decisivos para la vigencia de la etnicidad y la identidad cultural indígena.

Como resultado de la resistencia y asimilación a lo largo de los siglos desde una posición de subordinación y de asimetría a los centros de poder coloniales

(6) No olvidar que existen 1000 comunidades campesinas repartidas en sus 13 provincias. 
y oligarquías republicanas, en las comunidades muchos elementos culturales han cambiado de significado y otras han desaparecido en el tiempo fruto de la dominación. En tal sentido, los únicos reductos y depositarios de la matriz cultural andina los vamos a encontrar en las comunidades campesinas alejadas o con poca articulación a la sociedad moderna.

Segundo. La cultura andina se halla también vigente (con otros significados y bajo otras formas) en muchos migrantes, intelectuales y artistas de las ciudades. Este es un fenómeno esencialmente moderno que tiene como antecedente al movimiento indigenista de los años 20-30 en el Cusco siendo los estratos mestizos intelectuales de clase media quienes frente a la ignominia del abuso colonial-hacendatario reivindicaron la figura del indígena el cual había sido degradado bajo el concepto de "indio"; enfrentándose a las elites dominantes aristocráticas y la clase gamonal, a la iglesia, los jueces y la policía (el poder local) que controlaban hegemónicamente toda la vida económica, social, política y cultural de la época.

Al entrar en crisis el modelo oligárquico con los movimientos campesinos y la reforma agraria se abrió un espacio social y político para la eclosión de lo andino de múltiples formas: en términos económicos se dignificó al indígena al devolverle sus tierras, ello permitió que adquiera por primera vez la condición de ciudadano al ser reconocido socialmente como campesino en vez de indio y pueda acceder a servicios antes negados como escuela, salud, servicios básicos, carreteras y acceso a la modernidad. Culturalmente se valoró su gran aporte al conservar vigentes los componentes prehispánicos en sus comunidades.

Las clases medias cusqueñas ilustradas con mucha sensibilidad captaron estos cambios en el país y alentaron especialmente en el Cusco un movimiento de orgullo andino que utilizó y resaltó símbolos ancestrales de la cultura inca y de su grandiosidad como civilización para generar una conciencia cusqueñista cuyos iconos fueron la celebración del Inti Raymi, la creación de la bandera del Tahuantinsuyo, el escudo inca, el himno al Cusco y la celebración artística cultural de las fiestas en homenaje a la cultura incaica ${ }^{(7)}$. Por ello, no es casual que en la actualidad la cultura andina sea a veces más defendida y difundida por los mestizos citadinos de clase media que por los propios campesinos o migrantes.

\section{Lo andino en la ciudad del Cusco}

De las entrevistas realizadas con los actores sociales de la ciudad del Cusco, podemos distinguir dos tipos de pobladores: los sectores populares y los de clase media (alta y baja). Los primeros son toda la masa de migrantes, residentes de origen

(7) A ello se añade "los 4 grandes de la música cusqueña", la reivindicación de Clorinda Matto, el uso del término "qosqoruna" y la modernización andina de la ciudad por el alcalde Daniel Estrada. 
andino que viven y trabajan en todos los sectores de la economía principalmente en los sectores informales y pequeños negocios; tienen ingresos bajos y regulares que les permiten vivir en condiciones de pobreza y pobreza extrema a los cuales se les denomina o se autodenominan "cholos", "provincianos", "paisanos" ${ }^{\prime(\mathbf{8})}$. Los segundos son la enorme población de empleados públicos y privados, comerciantes, medianos empresarios, profesionales, artistas e intelectuales cuya condición socio económica es regular y a veces holgada, con buenas condiciones de vida.

Ambos grupos sociales comparten percepciones sobre lo andino de maneras extraordinariamente similares sin que ello anule o niegue las diferencias y expresiones de diferenciación social o fenotipica; ello debido a un elemento común a todo cusqueño (sea pobre o rico): ser heredero cultural de la sociedad inca y vivir en la cuna y capital del imperio incaico, siendo esta la esencia del sentimiento de orgullo que todos los grupos sociales denominan indistintamente "cultura andina", "identidad andina", "cusqueñismo" o "incanismo", cuyas expresiones se aprecian en las fiestas patronales religiosas, bailes, música, cargos, rituales, celebraciones y mil actividades a lo largo del año en colegios, instituciones públicas y actos públicos y de manera profusa en el mes jubilar del Cusco, donde se presentan exposiciones, eventos, desfiles, concursos, presentaciones artísticas, debates, coloquios y sin fin de actos conmemorativos de la grandiosidad de la cultura inca que culmina con la representación del Inti Raymi.

Estos elementos hacen distintiva la idiosincrasia cusqueña respecto a todo el Perú y especialmente frente al limeñismo como antípoda, por cuanto mientras en Cusco se reivindica la bandera y el corazón andino-inca y se cuestiona la dominación española, en Lima se mira al extranjero como paradigma y se hace loas al criollismo costeño bajo símbolos como ser"la capital de los reyes","gobernar desde el palacio de Pizarro", "la flor de la canela", "España la madre patria", es decir una ciudad pro hispana, sin alma, sin peruanidad. ${ }^{(9)}$

Este antilimeñismo está dirigido a los grupos de clase media alta y burguesía limeña que vienen al Cusco como turistas o de trabajo quienes asumen actitudes que ofenden el cusqueñismo andino como irrespeto a los monumentos arqueológicos, hacer ostentación de su poder económico, consumo de alcohol, drogas, y principalmente posturas de superioridad, discriminación y racismo contra los "cholos", "serranos", "provincianos" y la apreciación de lo andino en términos banalizados, reduciendo la riqueza cultural a lo exótico sin mayor comprensión del significado de estas expresiones culturales.

(8) Quienes lo asumen de manera ambivalente, con orgullo cuando se reivindica su cultura y origen y con dolor y vergüenza cuando son víctimas de racismo y discriminación.

(9) La peruanidad entonces es sinónimo de andino, de inca contrario al racismo y discriminación criolla que desprecia todo lo que significa andino, quechua, provinciano, serrano. Contrario también al discurso burgués dominante con carga peyorativa colonial hacia los que no son como ellos. 


\section{Percepciones sobre lo andino}

- Para los grupos sociales populares y los de clase media, lo andino está representado en la reproducción de las tradiciones cristianas coloniales como los cargos religiosos donde se combina lo sagrado y lo profano cuyo goce se aprecia en las danzas, el colorido de los trajes, el huayno, las qhashuas, el consumo de chicha, la bohemia de las picanterías, el folklore y consumo de alcohol en las "octavas", en las fiestas patronales, corpus, en los mitos alrededor de los santos. Alrededor de ellos el negocio, la economía de mercado.

- Lo andino también está en las ceremonias a la Pacha Mama, en los pagos a la tierera, las tinkas, hayhuarikuy, qapachiy, despachos, ritos de sanación, curaciones con medicina tradicional y hablar quechua en toda ocasión oficial o popular. Todo lo cual reproduce el orgullo prehispánico expresado con mucha fe tanto en el medio rural como en la ciudad.

- Lo andino implica también que todos los individuos (ricos, medios y pobres) pueden participar, interactuar y reconocerse en los mismos espacios físicos colectivos, fiestas donde todos comparten el orgullo de ser cusqueños descendientes del sol, aunque sus rasgos fenotípicos sean claros, oscuros, trigueños o morenos ${ }^{(\mathbf{1 0})}$.

- Lo andino también significa que las clases populares indígenas y mestizas accedan a la modernidad entendida en dos sentidos principalmente: acceso a la educación y su consiguiente profesionalización y el acceso a la ciencia y a la tecnología entendida como uso de la informática (internet y celular).

\section{Percepciones sobre lo indígena}

- Desde los grupos de clase media educada hay una connotación positiva hacia el indígena andino: se le ve y aprecia como el individuo descendiente de los incas, fuerte, alegre, festivo, lleno de sabiduría, rebelde como Tupac Amaru, ritualista, con religiosidad sincrética, creador nato del folklore andino (danzas, música, vestido, artesanía y gastronomía), artista, con conocimiento mítico y saberes que hay que "rescatar", "preservar", "conservar" y "promover"(11) por parte de las instituciones como el Ministerio de cultura, la Escuela de Bellas artes, las universidades, la municipalidad, los grupos artísticos, literatos e intelectuales.

- También dentro del cusqueño de clase acomodada, existe una connotación negativa de lo indígena cuando se lo asocia como sinónimo

(10) El cusqueñismo andino contemporáneo ha desechado conceptos como la "pureza" de piel, origen o apellido tal como se hacía hasta antes de la reforma agraria. Lo económico ha ayudado a disolver las discriminaciones por el color de la piel y el apellido.

(11) Discurso de las clases medias intelectuales y artistas con mucha sensibilidad, tal como ocurrió con el indigenismo de los años 20-30 del siglo XX. 
de "indio", es decir, degradado, inculto, ignorante, atrasado, sin educación; es común escuchar "se la salió el indio" como expresión de torpeza, grosería o reclamo. Esta carga peyorativa va de los mestizos de clase media hacia los populares, muchos de estos últimos han reproducido esta ideología para maltratar a sus propios paisanos.

- Estas percepciones contribuyen a polarizar el escenario y complejizar las identidades de los pobladores populares, quienes van a atravesar el eterno conflicto de no saber quiénes son: ¿andinos? ¿mestizos? ¿indígenas? es decir sentir orgullo o vergüenza; reconocerse como indígena o disfrazarse utilizando máscaras, tema identitario estudiado con mucho rigor por Rodrigo Montoya (1992) en su libro "Al borde del Naufragio". Resultado de este conflicto van a devenir categorías de auto identificación como es que a los cusqueños populares les gusta llamarse: "cholo", "provinciano", "quechua" o "mestizo".

\section{La discriminación a los andinos indígenas}

Un tema altamente preocupante es la subsistencia de expresiones de discriminación y racismo en el Cusco pese a que culturalmente casi todos los cusqueños compartimos la cultura andina, sin embargo, en algunos sectores sociales se ha instalado percepciones de resaltar las diferencias fenotípicas, étnicas y raciales entre las personas y los grupos sociales como distinción sociocultural. ¿Cuáles son las razones-pretextos para discriminar? ¿quiénes son las víctimas?

Como sabemos las prácticas discriminatorias reproducen ciertos valores culturales e imágenes sociales que influyen en las autopercepciones del grupo, donde se pone énfasis en las diferencias a partir de la separación jerárquica basada en los estereotipos y prejuicios (Benavides, 2006). En el caso peruano estos prejuicios se emiten desde los grupos de poder dominantes y que van a expandirse a la sociedad, afirmando una identidad en este grupo que necesita acentuar sus diferencias discriminando a los otros. La discriminación juega un rol importante en los procesos de conformación y definición de las identidades étnicas. Pero al mismo tiempo, las formas de respuesta de las personas están culturalmente condicionadas: responden a ciertos patrones propios de cada grupo étnico-racial (Valdivia, 2007).

En este marco se va a producir en las ciudades una tensión entre los sectores discriminados y los grupos discriminadores; dichas tensiones van exactamente a poner de manifiesto las "diferencias" sociales, raciales y étnicas entre los indígenas y los no indígenas. Veamos los testimonios:

"Yo soy de la provincia de Acomayo distrito de Pomacanchi, yo estaba aún en el colegio y cuando terminé las clases me vine de vacaciones a la ciudad 
del Cusco a trabajar, un día la dueña del lugar donde trabajaba nos invitó a una fiesta, era el cumpleaños de su hijo. Más tarde mi hermana y yo fuimos a la pequeña fiesta, así pasaron las horas y la madre de la señora repartía los bocaditos por todos lados, nosotros nos encontrábamos por la puerta y al momento que nos tocó, la señora se paró mirándonos de pies a cabeza y dijo "quien invito a esas cholas, que tienen que hacer aquí, que se vayan esas indias" y se fue a otro lado, la gente se quedó mirándonos y nosotras no sabíamos que hacer, nos retiramos y era asombroso como ninguna de las personas que se encontraban ahí dijera nada. Nosotras nos sentimos indignadas y sin poder hacer nada, preguntándonos ¿Por qué nos trató de esa manera? Supongo que la señora se sentía superior". M.S.M.

Soy de Chumbivilcas, una vez fui con mis primos a la ciudad de Arequipa y tuvimos que cenar en una pollería pero mis primos estaban con su ropa típica de Chumbivilcas, un sombrero y una casaca. No quisieron atendernos y un mesero murmuro "aquí no se vende chuño", así que nos retiramos de la pollería y cenamos en otro lugar. R.Q.T

Estas discriminaciones como señalábamos anteriormente, la desindigenizacion de las clases dominantes sigue expandiendo sus discursos polarizando las clases sociales y la identidad cultural en términos de separar o distinguir a los indígenas de los no indígenas bajo la figura del conflicto cultural que se reviste de clasificaciones étnicas como mestizos-criollos vs indígenas, cholos, migrantes en una relación positiva y negativa: la primera donde los primeros discriminan y los segundos asimilan el abuso (1). La segunda cuando los mestizos son tolerantes y los indígenas aprovechan para autoafirmar su cultura (2), tal como se aprecia en el siguiente esquema:

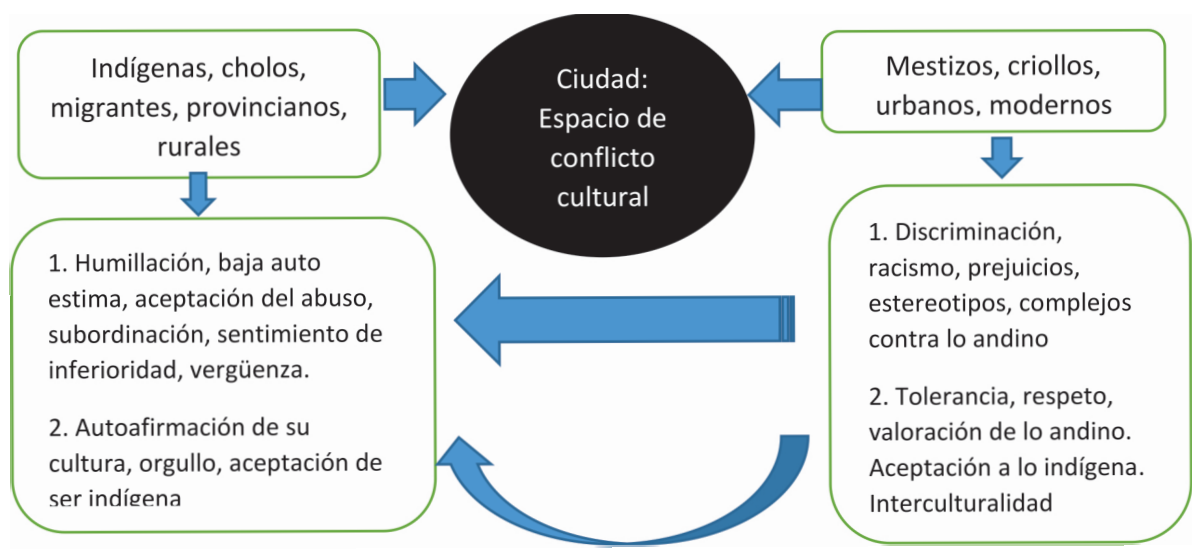


Ambas situaciones se dan en el Cusco. En el primer caso apreciaremos discriminaciones que la vemos cotidianamente y que nos parece "natural" que ocurra.

"Fui testigo de un acto de discriminación en la localidad de Sicuani, exactamente en la plaza de armas de dicha localidad en la puerta de ingreso hacia el banco de la nación, estaba haciendo la respectiva cola para recibir un giro, entonces a unos metros delante de mi había una señora del campo con la ropa tradicional; cuando la señora llego a la ventanilla le hablo en el idioma quechua a la señorita que atendía en dicha ventanilla entonces la señorita, yo no sé si en verdad no sabía el idioma o quizá no quería hablar en quechua porque la señorita le empezó a insultar a la campesina de muy mala manera y a levantarle la voz, inmediatamente las personas de la cola del banco empezaron a reaccionar, la señorita llamo al guachimán y la sacaron a la señora del banco". (B.Y.P)

"Otra discriminación ocurrió en el bus de servicio público León de San Jerónimo cuando una persona de la tercera edad que era de provincia subió al colectivo y le ceden el asiento, al poco rato la señora que estaba a su lado comenzó a murmurar diciendo que "había un mal olor en el bus y como permitían que suba gente cochina." Los demás no dijeron nada. (R.P.U)

En el segundo caso, donde la relación étnica-cultural entre mestizos, criollos e indígenas y cholos es horizontal y de respeto, se producen casos de afirmación identitaria como los siguientes:

"Si, soy indígena quechua chola porque mi apellido desciende de los caciques de Espinar porque son fuertes, no se rinden y porque son trabajadores. Otro punto, me enseñaron a hablar quechua fluido $y$ aunque tuve que migrar al Cusco y siempre me han tratado bien, por eso mis costumbres sigo realizando como el pago a la tierra, rezar a los apus y trabajar la agricultura. Mi familia sigue llevando sus costumbres tradicionales, pero con el pensamiento de los antepasados, pero nosotros en el siglo XXI en la ciudad pensamos de manera diferente con la ciencia y la tecnología, pero nunca nos olvidamos de nuestra tierra" (A.P.T)

"Yo me considero quechua y chola porque nací en la ciudad del Cusco, tengo peculiares rasgos andinos que me identifican así, porque de parte de mi mama soy campesina indígena y de mi papa somos de origen puneño. A pesar de todos estos orígenes soy también moderna-mestiza y me siento orgullosa de serlo porque en la ciudad siempre he encontrado las oportunidades y no me han discriminado" (L.V.P.) 


\section{Expresiones de discriminación en el Cusco}

Las expresiones de discriminación y/o racismo ocurre en individuos que reproducen la ideología colonial burguesa y se da verticalmente de los citadinos mestizo-criollos hacia los migrantes provincianos de origen quechua, a los hijos de estos que estudian en la ciudad, a los residentes andinos ya establecidos que trabajan en los sectores informales, en pequeños negocios y microempresas familiares; en fin, a los "cholos" que se han aculturado y que tienen rasgos étnicoraciales rápidamente identificables ${ }^{(12)}$ que viven en la ciudad del Cusco y que interactúan con los miembros de las demás culturas criollo-mestizas y extranjeras. Ellos sufren discriminación en las siguientes formas:

1) Impedimento de ingreso a lugares públicos por su condición de campesinos, indígenas para el ingreso a lugares arqueológicos, centros comerciales, hoteles, restaurantes, discotecas.

2) Maltrato, insultos, desprecio o acciones de violencia en las instituciones, bancos, buses por parte de los pobladores urbanos mestizos, pero también por parte de migrantes que trabajan como serenos, "wachimanes", policía nacional, soldados que son de origen andino instalados en la ciudad.

3) En los colegios, por su origen, apellidos, color de piel, situación económica o apariencia por parte de muchos profesores y compañeros

4) Engaño, aprovechamiento en precios, pesos y medidas a los productores indígenas que traen sus productos al mercado, por parte de comerciantes y compradores urbanos (mestizos populares y de clase media respectivamente)

5) En los centros comerciales, el personal maltrata a los clientes andinos con prejuicios de ser "rateros", "no es para ellos", "son pobres, no compran nada".

6) Por la ropa y apariencia física contra las mujeres indígenas que usan polleras, qepes, ojotas, uncuñas, Iliqllas maltratadas como "sucias", "ignorantes".

7) Por no saber comportarse como en la ciudad: saludar-despedirse con un beso, vestir según la ocasión, bailar, etc.

8) A los usuarios indígenas se les maltrata en la atención de ventanillas al público en municipios, bancos, instituciones públicas, empresas privadas, ministerios por cuanto los empleados no saben quechua y no entienden sus pedidos.

(12) Con marcadores culturales como idioma, lugar de nacimiento, apellidos, vestido, costumbres, comida, color de piel, barrio donde viven, círculo de amigos. 
9) Por la forma de hablar con "motes" rápidamente son discriminados en toda relación social o evento, siendo motivo de burla.

10) Por el trabajo que desempeñan: son vendedores ambulantes, trabajadores de mercados, de limpieza, serenazgo, personal de servicio, taxistas por parte de todo citadino con la famosa frase "no sabes con quien te metes", "indio de...."

En muchos casos esta discriminación se da entre los propios indígenas o migrantes que reproducen la enculturación excluyente.

"Mi madre sufrió un caso grave que era discriminada por la procedencia, es de Qeros Paucartambo; a los 3 años se vino a la provincia de Paucartambo vivió ahí toda su infancia y juventud, allí conoció a mi padre y se casó a los 22 años pese a todo esto sufría discriminación étnica de los mestizos, pero también de mi padre que era mestizo; bueno ella nunca se avergonzaba pero la discriminaban mucho. A veces llegaban familiares de mi madre de visita pero eso a mi padre le molestaba en algunos momentos, le insultaba a mi madre por su origen; en correspondencia o por no quedarse atrás mi madre le discriminaba a mi padre por su color ya que es un poco moreno. Es así como mi infancia estuvo acompañada de discriminación. Pero a mí no me gusta la discriminación, lo he reflexionado y me siento más orgulloso de mi procedencia, de mi raza y de la cultura a la que pertenezco, soy indígena andino". (A.H.Q)

Finalmente, una situación preocupante, es la discriminación por género, es decir además de las diez razones expuestas se añade la condición de ser mujer, peor si es indígena, en ella se va sintetizar -como diría Vallejo "todo el odio de dios" para sufrir las más humillantes discriminaciones, lo que evidencia de que además de ser una sociedad racista el machismo se añade como parte de la opresión cultural. Leamos los testimonios:

"Fui discriminada en muchas ocasiones, pero lo más relevante fue cuando viajé a Lima por motivos de trabajo, estando en tercer año de secundaria. Inicialmente estaba emocionada porque era mi primera vez saliendo de mi pueblo y era un sueño conocer Lima, pero fue la peor experiencia de mi vida. Comencé a trabajar como empleada de hogar en una casa en San Juan de Lurigancho, los primeros días me trataron bien pero no sé qué paso con la señora que cambio repentinamente y empezó a tratarme de "india", cochina, e incluso no quería que coma la comida que ellos comían, no quería que me haga trenzas y me obligó a cortarme el cabello. No le gustaba nada de lo que hacía ni como me vestía. No aguante más y le dije que quería irme, ella lo tomo con calma y me dijo que me despacharía a 
mi pueblo, sin embargo, empezó a llamarme ladrona me dijo que le había robado dinero y no me quiso pagar. Al final no me pagó, solo compró mi pasaje, inventó cosas que se las dijo a mis padres para cuando regrese recibí su castigo, fue la peor época de mi vida". (G.J.H)

"Cuando estaba en la escuela mis compañeras me excluían de su grupo de actuación y si ponían era para un papel secundario. La compañera que dirigía el grupo era hija de familia de economía y su madre era de Quillabamba y a casi todas mis compañeras nos insultaba diciendo que éramos cholas, también cuando era elecciones ella nos decía que el partido del APRA era el mejor y que los demás partidos eran solo de serranos, y que nosotras éramos unas pobretonas, así nos maltrataba porque tenía el respaldo de la profesora que era del Cusco" (M.CH.F)

"Cuando entré a trabajar en una tienda de tejidos, pues la señora que me contrato era de Lima, quien todo el tiempo se la pasaba diciéndome "chola", "india" cuando se molestaba de algo, me insultaba cuando algo le molestaba "eres una india, chola, hueles a llama" entre otras cosas y una al escuchar esas palabras se hace menos, te sientes inferior que los demás. Lloraba por dentro, aunque en ese momento te encorajas y demuestras que ese insulto no te hace daño, pues por dentro te molieron. Al salir del trabajo buscaba llorar, pensaba ¿porque me tratan así? ¿Por qué la crueldad de la gente que te hace daño gratuitamente? Eso paso cuando tenía 17 años donde aún no reconoces porque ese trato discriminatorio. Hoy no recibo ese tipo de insultos, pues aprendí a decir que el indígena es más que tener plata, es algo que te da fuerza para salir adelante en la vida." (I.C.Y)

Estos testimonios ponen al desnudo los esquemas patriarcales de la sociedad que ubica roles predeterminados a varones y mujeres (con mis hijos no te metas) que reafirma posiciones subordinadas de las mujeres en la sociedad de sometimiento al varón a la estructura societal y cultural; donde se naturaliza la violencia contra la mujer como parte de sus roles, peor aún si su condición étnica es indígena, tiene que vivir sometida, sumisa y donde la reiteración de su condición de inferioridad étnico-cultural combinada con la situación socioeconómica de pobreza, es manifiesta para manipular el sometimiento.

Lo importante de estas experiencias es que todas las mujeres que las sufrieron percibieron las estructuras del poder (familiar, económico y cultural) y asumieron una actitud crítica de rechazo y el deseo de romper con estos patrones de dominación. 


\section{Conclusiones}

a) Conceptualmente la cultura andina no es solo la herencia prehispánica inca sino que ha asimilado e incorporado contenidos coloniales y modernos en una síntesis muy rica y dinámica que se expresa en las ferias, fiestas, ceremonias, festivales artísticos donde se habla en español y en quechua atravesando la estructura social urbana y rural regional a lo largo del año; manteniéndose con mayor fuerza en las comunidades campesinas más alejadas y en las ciudades. Esta cultura, sin embargo, no está ajena a los influjos de la modernidad y de la globalización dentro de una economía de libre mercado; por ello la tarea que queda es el discernimiento de sus rasgos positivos de los negativos para evitar la erosión cultural de lo andino.

b) La cultura andina sigue vigente y tiene continuidad histórica recreándose dentro de la sociedad globalizada. Lo andino se vive de manera especial en el Cusco dando origen al "cusqueñismo", tanto en la ciudad como en el campo abarcando a todos los sectores sociales y étnicos como indígenas, cholos, mestizos y población citadina quienes comparten el orgullo de la herencia inca como símbolos de identidad. Es decir, pobres y ricos todos compartiendo los elementos de una misma cultura.

c) Se evidencia también el conflicto cultural desde las estructuras de poder a partir de la des-indigenizacion y como los sectores hegemónicos de la sociedad buscan imponer su modelo occidental-globalizador en términos culturales para la predominancia de la cultura criollo-mestiza en desmedro de los pueblos indígenas andinas. Por dicha razón las clases subordinadas terminan asumiendo el discurso dominante para asimilarse a la sociedad y cultura moderna implementadas estrategias orientadas al blanqueamiento social y la aculturación.

d) Los factores de discriminación y racismo se dan en contextos urbanos y de relaciones de poder de los sectores económicamente acomodados contra las poblaciones descendientes de indígenas utilizando marcadores culturales de origen, posición económica y fenotipos étnicos; más aún de manera doblemente excluyente con una carga ideológica mezcla de racismo-genero-clase cuando se trata de discriminar a mujeres indígenas. 


\section{Bibliografía}

BONFIL, Guillermo. 1990. México profundo. Una civilización negada. Ed. Grijalbo

BENAVIDES, M y Callirgos J.C. 2006. Nota técnica sobre indígenas y afro peruanos. Informe de investigación. Grade, Lima.

COTLER J. 1968. La mecánica de la dominación interna y del cambio social en el Perú. IEP, Lima.

DEGREGORI, C.I. 2014. El aprendiz de brujo y el curandero chino. Etnicidad y modernidad en el Perú. IEP, Lima

DEGREGORI, C.I. 2000. No hay país más diverso. Manual de antropología peruana. PUCP-IEP, Lima.

De la Cadena, M. 2004. Indígenas mestizos. Raza y cultura en el Cusco. IEP

MANRIQUE, N. 1993 "Algunas reflexiones sobre el colonialismo, el racismo y la cuestión nacional", en La Piel y la Pluma, escritos sobre literatura, etnicidad y racismo. SUR-CIDIAG.

MONTOYA, R. 1992. Al borde del Naufragio. Democracia, violencia y problema étnico en el Perú. SUR casa de estudios del socialismo. Lima.

MONTOYA, R 1980. Capitalismo y no capitalismo en el Perú. Un estudio histórico de su articulación en un eje regional. Mosca azul edit. Lima.

MONTOYA, R. 2005. De la utopía andina al socialismo mágico. Antropología, historia y política en el Perú. Instituto Nacional de Cultura - Cusco.

QUIJANO, A. 2000 "Colonialidad del poder y clasificación social" Journal of Woldsystems research, $\mathrm{Vl}, 2$ Summer/fall en Inmanuel Wallerstein- part I. Dep. of Sociolgy. State University of New York.

VALDIVIA, N y BENAVIDES M 2007. Exclusion, identidad etnica y politicas de inclusion social en el Peru: el caso de la poblacion indigena y la poblacion afro descendiente. Grade, Lima. 